\title{
Comparative Affect of Candidates' Physical Attractiveness between Resume Screening and Interview Process Outcomes. Empirical Research for Greece
}

\author{
Andreas Dimopoulos \\ PO Box 3118, Fragma Thermis Post Code 57001, Thessaloniki Greece \\ E-mail: job1j@yahoo.gr; info@andreasdimopoulos.gr \\ Andreas Dimopoulos (Corresponding author) \\ PhD Candidate, Department of Economics \\ Faculty of Social, Political, and Economics Sciences-Department of Economics, \\ Democritus University of Thrace \\ Panepistimioupoli, Komotini 69100, Greece \\ E-mail: secr@econ.duth.gr
}

Received: July 8, 2019 Accepted: July 26, 2019 Online published: August 6, 2019

doi:10.5296/ijhrs.v9i3.15226 URL: https://doi.org/10.5296/ijhrs.v9i3.15226

\begin{abstract}
Many factors can affect recruiters, personnel managers or employers during employee selection process such as degrees and other typical qualifications of candidates the possess of the right transferable skills, the knowledge of job market, their working experience, the combination of personal attributes, self presentation skills, personality. Apart of them and many others factors, there is a consensus in a large extent, that candidates' physical attractiveness can affect recruiters' decisions during employment selection process, both in first stage of screening their curriculums' vitae, as well as in the second stage which is the interview hiring process. This study aims to search the role of employee candidates' physical attractiveness and its comparative impact between first stage of screening applicants according to their resumes and second stage of hiring decisions during employment interview. For this purpose, an empirical research has been conducted in order to explore the importance
\end{abstract}


and relative impact of candidates' physical attractiveness in decisions and selection process outcomes. In particular we asked two hundred and sixty recruiters', personnel managers' and employers in Greece about the impact of candidates' physical attractiveness might have in their recruiting and hiring decisions. Results show that physical attractiveness influence recruiters decisions and affect selection outcomes in both selection stages. The impact is higher and statistically more significant in interview process. Physical attractiveness also compared to resume quality in order to explore relative impact among these factors. Results show a greater influence of resume quality than physical attractiveness.

Keywords: interview, employment, resumes, selection, recruiting, attractiveness

JEL codes: M51, M12, J23, J21, J80, J62, 015, L20, D21, D23, F23

\section{Introduction}

\section{The process of employee selection}

Attracting and selecting staff is one of the most important processes for any business, and is often considered to be the most important (Sivabalan, Yazdanifard, \& Ismail, 2014). The main purpose of the personnel selection procedure is to select the appropriate candidate who meets the needs of the company (Gamage, 2014). It is also argued that in order to achieve and maintain the competitive advantage of an enterprise, the choice of suitable staff is crucial (Djabatey, 2012). The whole process of hiring a candidate starts from the announcement of the job posting in such a way that candidates related to the available position can be informed about it. This is the stage of attracting the candidates which aims to encourage the appropriate ones to manifest interest in the position requested. Then the next stage is the concentration and ranking of the CVS depending on the importance of each one making the short list. Finally follows the final stage that is the selection process through various methods of the most suitable candidate from the final list that has emerged (Bartram, 2000). The interviews are used as a means of recruitment, at the global level (Huffcutt \& Culbertson, 2011). Typically, the interview begins with the examination of the credentials of the candidates as they appear on the application form, or on their resume, then the face-to-face interview is followed, and the process ends with the final evaluation of the candidates' qualifications (Dipboye et al., 1984). The impressions that the interviewers make for the candidates before the interview with them are associated with these decisions and after (Cable \& Gilovich, 1998). Research has shown that decisions related to recruitment are made based on both objective qualifications (e.g. person to the job fit, person to the organization fit) and subjectively (Wade $\&$ Kinicki, 1997). Sometimes, impressions created by subjective qualifications affect decisions on recruitment of staff significantly more than those of objective qualifications, due to the emotive effect (Roebken, 2010). Staff selection officers evaluate more favourable candidates who are subjective attractive, than unattractive co candidates, as well as that subjective impressions reinforce the perception of person suitability to the job between individuals and hence affect the job proposals (Davison et al., 2011). For example, candidates' particular views or resumes background information may enhance the sense of 'identification', similarity with staff managers, recruiters or enhance the emotive effect, which can strengthen the intentions of them towards the candidates' (Rynes, Barber, and 
Varma, 2000). Overall, attractive individuals were benefited with more favorable job outcomes, such as selection, performance evaluations, and hiring decisions, than unattractive individuals (Hosoda, Stone-Romero, and Coats, 2003; Shahani-Denning et al., 2011). Attractiveness influences hireability through two dimensions of value, social desirability which is about the approachability of an individual and social utility referred to the individual's likelihood of success or failure hinging upon how well they can meet society's standards. Due to its consistent influence on the interviewer's decision-making process, attractiveness is undoubtedly a factor in employee selection (Descrumaux, De Bosscher, and Léoni, 2009). For clarification purposes a distinction among physical attractiveness and sexual attractiveness should be made. Sexually attractive individuals display traits indicating sexual maturity and reproductive fitness. This contrasts the concept of physical attractiveness, a more general evaluation (Wade, 2000, 2003)

Problem statement: it is obvious that recruiters, personnel managers and employers during employee selection process assess many typical qualifications of candidates such as knowledge of the labor market, possession of necessary skills, self confidence, previous working experience, and many others. On the other hand according to literature review there is evidence that selection decisions depends not only on formal qualifications but also on other factors which are subjective criteria, such as effective self presentation skills, impression management tactics, and physical attractiveness. The main research question is, if the subjective qualification of physical attractiveness as selection criteria has a greater, or equal influence than the total 'quality' of a candidate's resume in selection decisions which if it occurs then leads in bias and discrimination. Thus this study aims to investigate and to support, or reject the theory of physical attractiveness influence in Greece personnel selection practices considering the opinion of Greek recruiters, personnel managers and employers.

\subsection{Physical Attractiveness-Literature Review}

\subsubsection{Impact of Physical Attractiveness during Resume Screening}

The attractiveness of the candidate is confirmed to affect the decision of the interviewers positively for the attractive candidates in relation to the non-attractive in the process of examining their CVs and in particular by criteria their willingness to hire and offer them a higher starting salary. However, this positive effect of attractiveness applies only in cases of candidates who are not highly qualified and, conversely, when it comes to highly qualified candidates, the influence of attractiveness is almost insignificant. The most attractive candidates are also favored at the level of remuneration in relation to non-attractive candidates (Dipboye, et al 1977). The attractive candidates are favored both in terms of suitability and their ranking in relation to non-attractive candidates, in particular in the case of managerial positions. Of course the attractiveness as well as the gender as evaluating factor of the candidates in the 'examination' process of the resume is of lower weightiness and importance than other criteria such as for example the higher scholastic standing. But as parameters gender and attractiveness are equally important and measurable when it comes to comparison between candidates who possess at the same level high qualifications, most qualified candidates (Dipboye, et al 1975). 
Attractiveness during the evaluation stage of the CVS is a privilege, an advantage when the 'quality' of the candidate's CV is on average. So when it comes to candidates with moderate resumes, then the attractive candidates based on the photo attached in their $\mathrm{CV}$, are graded higher, highlighting thus a relative bias between these candidates who may have equivalent qualifications. So between candidates with a modest CV but with an attachment of an attractive photo it is more likely that they will be invited for an interview compared to the candidates who had the 'same CV' but did not attach an attractive photo. The attachment of a moderate to attractive photo had no effect on the evaluation of candidates among which there were differences in their CVs. In other words candidates who had better resumes and did not attach photos were not graded below by candidates who had worse resumes. For candidates with high quality resumes the existence of a photograph does not affect the rating and the evaluation, but it is noted that an attractive candidate with an average $\mathrm{CV}$ is considered to the same extent employable with one also attractive candidate who has a higher quality $\mathrm{CV}$ (Watcins and Johnston, 2000).

However, the quality of the resume also plays an important role, which means that candidates with high quality resume are graded more positively compared to poorer resumes when the attractiveness of these is on average (Watcins and Johnston 2000, p. 80, 81). Candidates who list in their CV a photo in which they appear 'especially' smiling enhances their chances of being hired as long as they have the necessary working skills. In other words, the employment skills are more important as criteria for hiring someone, but the attractiveness and the smile reinforce the rating of the remaining job qualifications, criteria (Abel, and Deitz, 2008). Physical attractiveness and appearance was further explored either as unimportant or important as well as a picture of a male or female that was considered attractive or unattractive and participants were asked how suitable they believed that individual to be for a position. The results indicated that overall attractive applicants were rated as more suitable for employment with some exceptions for men applying to masculine jobs as opposed to feminine jobs (Johnson, et al., 2010).

In another research an analysis of physical attractiveness impact results, among different cultures of Indian and American samples support the notion "beauty is beastly" stereotype for participants of US sample, with attractive males received the highest ratings and the attractive female received the lowest ratings. While the results of the Indian sample support the notion 'what is beautiful is good' stereotype (Dion, Berscheid and Walster, 1972) with the attractive female and male applicant being perceived to be more qualified, more likely to be hired and to receive a higher salary than the unattractive (Shahani-Denning, et al, 2010).

While the most common finding in the selection literature is that unattractive applicants are rated less favorably than attractive applicants, some studies have results counter to the "beautiful is good" hypothesis. Some evidence suggests that when the position being applied for is traditionally filled by a male, the reverse of the typical bias is found for female applicants: Attractive females are evaluated less favorably than unattractive females (Heilman and Saruwatari, 1979) labeled this the "beauty is beastly" effect. 


\subsubsection{Impact of Physical Attractiveness during Interview Process}

Attractiveness and reliability have been proven to affect the results of an interview (Gilmore, et al.,1986; Schmitt, 1976). The physical attractiveness of candidates increases the sympathy, likebility of interviewers to them and thus increases their chances of hiring (Cash, et al. 1977). Physical attractiveness affects the interviewers during the interview and prospective men and women who are attractive are perceived as more sociable, responsive, confident and efficient in their daily lives, when there are tasks with personal, formal relationships (Subhani, $2012 \mathrm{p}$. 6). Also, the attractiveness significantly strengthens the estimation of interviewers towards the suitability for hire of candidates (Kinicki \& Lockwood, 1985, p. 123). The special positive influence which exerted by physical attractiveness of a candidate in the decisions of interviewers confirm other investigations. (Arvey, \& Campion, 1982; Dipboye, 1992; Cable., et al.,1997).

Also another research researching the effect of gender and attractiveness in the process of evaluation and selection of candidates states that both as factors influence the decision of the interviewers on the acceptance of candidates. More specifically, the less attractive candidates as well as the women were lagging behind in scores and rankings compared to the most attractive candidates and men (Marlowe, et al., 1996).

The expectations of candidates for a successful interview are positively related and to a significant degree even with the image they have themselves for their external appearance (body satisfaction) but much more with their self-esteem (King and Manaster, 1977, p. 591,592). Personal appearance of a candidate is an interesting criterion at least for the first interview as mentioned in another survey (Bartram, et al 1995). Appearance and handshake are two sources of bias during the first stage. Final decisions are greatly influenced by the appearance of the candidate when it comes to unstructured, informal interviews, which is not the case in structured interviews, as people who receive interviews scarcely affected by the appearance of the candidate. Also appearance is not related to performance later on work place (Barrick et al., 2009). The attractiveness and impressions during the interview are significantly related both to the criterion for suitability for hire and to the criterion 'Interviewing skills', while gender and similarity to recruiter, work experience, and academic achievements were not found to be related to any of the above criteria (Kinicki and Lockwood, 1985). Also, physical attractiveness of candidates seems to affect the interviewers during the interview through impression management tactics that candidates take advantage of. In the first category of these strategies -strategic tactical assertive- are included: physical attractiveness, self-esteem, prestige, status, credibility and usually are used to serve long-term goals and interests, strategic interests) (Tedeschi and Melburg,1984).

Results also indicate that applicant attractiveness and the relevance of attractiveness to job position interacts affecting hiring decisions. More attractive individuals were hired for the position for which physical attractiveness was relevant (Beehr and Gilmore,1982). Attractive applicants were rated also as more suitable for occupations where appearance was perceived as important factor than for jobs for which appearance was perceived as unimportant (Johnson, et al.,2010) 


\section{Methodology}

To study our research questions about the relative impact that physical attractiveness might have on selection process, a primary field research was conducted. In our empirical survey participants were asked through a structured questionnaire to state the extent of possibility and significance they accredit to applicants' physical attractiveness during staff selection process. In particular we examine the possible influence could have physical attractiveness of candidates on recruiters hiring decisions during the first stage of selection process which is screening of their resumes and in the second stage which is interview process.

Specifically, investigated the extent to which recruiters consider that candidates' physical attractiveness could has an impact to their decisions a) to call him for an interview, b) to consider him suitable for the position, and c) to rank him in the short list in the first stage of screening their resumes, while at the second stage of interview process we examine the possible influence candidates' physical attractiveness could has on their hiring decisions which were a) to hire them, b) to consider them suitable for the position and c) to give them a chance for a second interview. Three overall are the objectives of this investigation. Firstly, to investigate whether physical attractiveness affects the decisions of the interviewers, secondly to consider whether there is a difference in the degree of influence of candidates' physical attractiveness between the stages of the evaluation of their CVs and their evaluation at interview stage. Thirdly to consider the comparative effect and relative importance of physical attractiveness in decisions of the interviewers in comparison, on the effect of the quality of the candidates ' $\mathrm{CV}$ and qualifications.

\subsection{Formulation of Research Questions at the Stage of Resume Screening}

In order to formulate the questions for the level of significance of physical attractiveness at the stage of resume screening we have taken into account various research related to the staff selection with resume screening process.

The literature review mentions a series of indicators of 'measurement' of the effectiveness and attractiveness of a $\mathrm{CV}$, and most surveys highlight the following more specific 'valuations': inviting the candidate to an interview (Watcins and Johnston 2000; Thoms, et al.,1999; Brown \& Campion, 1994; Werbel and Looney, 1994). Elsewhere the success of a resume is defined in the sense of candidate suitability for the position (Dipboye, et al 1975; Bright and Hutton, 2000), the decision of the evaluators to invite him for an interview and the overall ranking of the CV (Bright and Hutton, 2000). Another survey describes the efficiency of a $\mathrm{CV}$ with the term potential for recruitment (hire ability) of the candidate or the perception of the applicant fit for the job of recruiters. (Knouse,1994). Thus, the choices of interviewers concerning the influence of the candidates' physical attractiveness in their decisions related to the first stage of the evaluation of their biographical notes, are precisely the following a) their decision on the basis of the candidate's CV to invite him initially to an interview, b) their decision based on the candidate's CV to consider him appropriate for the position, c) their decision based on the candidate's CV to rank him in the list of the prevailing. We ended up with the above dependent variables using the entire existing corresponding bibliography but mainly relying on the surveys of (Bright and Hutton. 2000, p. 8; Brown and Campion, 1994, 
p. 904) which aggregate all three variables. It is considered a more 'strictly' criterion, or otherwise final stage in the process related to the evaluation of CVS, the invitation of a candidate to an interview. The ranking of a candidate in the list of the dominant, despite his approval as suitable for the position, follows a series of significance for the simple reason that other applicants as well can be considered on the basis of their CV suitable for the position, or even to join the short list. However, what is regarded as the epitome of the original process and as a final conclusion is the invitation of the most successful candidates to an interview. To study the effect of candidates' attractiveness which is determined on the basis of the attachment of the relevant type of identity photography to interviewers decisions while they evaluate applicants resume, in relation to the quality of their $\mathrm{CV}$, we used as research base a relevant study (Watcins \& Johnston, 2000, p. 79, 80). The determination of the quality of the resume was made on the basis of the evaluation of the data relating to the educational background, working experience, achievements, positions of responsibility held, interests and academic records

\subsection{Formulation of Research Questions at the Stage of Employment Interview}

In order to formulate the questions for the level of significance of physical attractiveness at the stage of interview we have taken into account various research related to the staff selection interview process. So we chose to focus on three versions of results that are the most common success indicators of an interview as evidenced by the majority of the literature review. An employment interview usually has the ultimate goal or often ends in the following: hire or recommendation to hire (Gilmore \& Ferris 1989, p.561, 562; Higgins \& Judge 2004), b) possibility of inviting candidates to a second interview (Burger \& Caldwell., 2000, p. 51-62; Caldwell \& Burger., 1988, p.126; Wei-Chi Tsai, et al., 2005 p.113; Stevens \& Kristof, 1995) and to consider a candidate as suitable for the job position (Kinicki \& Lockwood, 1985; Wei-Chi Tsai, et al., 2005, p.113; Stevens \& Kristof, 1995). Based on these indicators we examine the influence of candidates' physical attractiveness on recruiters hiring decisions at the second stage of interview process to the following choices a) to hire them, b) to consider them suitable for the position and c) to give them a chance for a second interview. So we have asked the following questions in order to measure the impact of candidates' attractiveness on the evaluators' decisions but also to monitor the relative interaction of attractiveness in relation to quality (high training, working experience, studies, etc.) of a CV.

\subsection{Research Questions}

The significance, effect of attractive appearance in the stage of resumes evaluation (based on attached photo)

In order to investigate the effect of attractiveness in the process of evaluating the CVS of candidates we have asked the following question 'Based on a candidate's CV, how likely it is: a) to call him in an interview, b) Do you consider him appropriate for the position and c) classify him in the short list if: (i) his appearance is in your opinion attractive? (Watcins \& Johnston, 2000)

The significance, impact of physical attractiveness in relation to the quality of $C V$ 


\section{$\Lambda$ Macrothink}

In order to investigate the relationship, weightiness between the attractiveness of the candidate and the quality of their $\mathrm{CV}$ in the process of evaluating candidates ' CVs we asked the following question, 'based on $\mathrm{CV}$ of a candidate how likely it is: a) to call him in an interview, b) consider him appropriate for the position and c) classify him in the short list if: a) he has a high quality CV (i.e. significant experience-studies-discrimination) and low attractiveness and b) has a 'low' quality $\mathrm{CV}$ but a particular attractiveness (Watcins \& Johnston, 2000, p. 79,80).

Participants were able to answer the above questions on a Likert Scale type rating scale from one (1), where $1=$ no possible, up to five (5) where $5=$ highly probable

The significance, impact of physical attractiveness in the interview stage

In order to investigate the influence of physical attractive appearance in the decisions of the interviewers we relied on the survey of (Hornsby et al 1995, p. 4) and we asked the question "How much emphasis you attribute on the appearance, attractiveness of the candidate. More specifically, how important, significant it is physical attractiveness for you when you select candidates with the interview method in your decision to a) hire him, b) consider him suitable for the position and c) give him an opportunity for a second interview. As an appearance, physical attractiveness we defined the natural attractiveness, appearance, subjective beauty of the candidate.

Participants were able to answer the above questions on a Likert Scale type rating scale from one (1), where $1=$ not at all significant, up to five (5) where $5=$ highly significant

\subsection{Research Hypothesis}

Hypothesis 1: There is a positive correlation between physical attractiveness and recruiters decisions on resume screening (based on a relative attached photo of candidate)

Hypothesis 2: There is a positive correlation between physical attractiveness and selection interview outcomes (based on physical appearance of candidate on interview)

Hypothesis 3: Impact of physical attractiveness is equal, equivalent, among resumes screening and interview process outcomes

Hypothesis 4: Impact of applicants' with high quality resume and qualifications but less physical attractiveness, is expected to be higher to recruiters selection decisions', compared to applicants' with higher physical attractiveness but less quality of resume

\section{Statistic Analysis}

In order to present the answers given during the interviews, frequency allocation tables were constructed for each question in the questionnaire. The Spearman correlation coefficient was calculated to investigate the correlation between respondent opinions / attitudes. The checks were carried out at a confidence level of 0,05. Analyzes were conducted using IBM SPSS Statistics (IBM SPSS Statistics for Windows, version 19 (IBM Corp., Armonk, N.Y., USA) 


\subsection{Reliability Analysis}

Table1.Reliability Analysis. Physical Attractiveness impact on hireability-sellectability index in stage of resume screening

\begin{tabular}{r|r}
\multicolumn{2}{c}{ Reliability Statistics } \\
\multicolumn{1}{c}{$\begin{array}{c}\text { Cronbach's } \\
\text { Alpha }\end{array}$} & N of Items \\
\hline, 881 & 3 \\
\hline
\end{tabular}

\begin{tabular}{l|r|r|r|r}
\multicolumn{5}{c}{ Item-Total Statistics } \\
$\begin{array}{c}\text { Physical } \\
\begin{array}{c}\text { Attractiveness } \\
\text { impact on } \\
\text { hireability }\end{array}\end{array}$ & $\begin{array}{c}\text { Scale Mean } \\
\text { if Item } \\
\text { Deleted }\end{array}$ & $\begin{array}{c}\text { Scale } \\
\text { Variance if } \\
\text { Item Deleted }\end{array}$ & $\begin{array}{c}\text { Corrected } \\
\text { Item-Total } \\
\text { Correlation }\end{array}$ & $\begin{array}{c}\text { Cronbach's } \\
\text { Alpha if } \\
\text { Item Deleted }\end{array}$ \\
\hline $\begin{array}{l}\text { q13.1i=call for } \\
\text { interview }\end{array}$ & 5,3692 & 4,249 &, 684 &, 906 \\
\hline $\begin{array}{l}\text { q13.1p=consider } \\
\text { suitable }\end{array}$ & 5,7269 & 3,805 &, 861 &, 751 \\
\hline $\begin{array}{l}\text { q13.1sl= short } \\
\text { listed }\end{array}$ & 5,6962 & 3,857 &, 772 &, 830 \\
\hline
\end{tabular}

For the stage of resume screening regarding physical attractiveness' impact on recruiting decisions the three choices of recruiters a) to call him for an interview, b) to consider him suitable for the position, and c) to rank him in the short list, has been unified in one index, which we called hireability, sellectability. We also did the same for the next stage which is interview selection process and three choices of recruiters a) to hire them, b) to consider them suitable for the position and c) to give them a chance for a second interview has been unified in one index, which we called again hireability, sellectability. The term, index has been used also in other research (Cuddy, et al, 2015; Knouse, 1994). The values of this new index were calculated for both stages, for each participant in the sample as the average of the above three grades of agreement (tables 1,4))

Table 2. Reliability analysis of the combination impact of high quality resume and low physical attractiveness on hireability- sellectabillity index

\section{Reliability Statistics}

\begin{tabular}{r|r}
\hline Cronbach's Alpha & N of Items \\
\hline, 802 & 3 \\
\hline
\end{tabular}




\begin{tabular}{l|r|r|r|r}
\hline $\begin{array}{l}\text { Item-Total Statistics } \\
\text { with low }\end{array}$ & $\begin{array}{c}\text { Scale Mean } \\
\text { if Item } \\
\text { attractiveness }\end{array}$ & $\begin{array}{c}\text { Scale } \\
\text { Variance if } \\
\text { Item Deleted }\end{array}$ & $\begin{array}{c}\text { Corrected } \\
\text { Item-Total } \\
\text { Correlation }\end{array}$ & $\begin{array}{c}\text { Cronbach's } \\
\text { Alpha if Item } \\
\text { Deleted }\end{array}$ \\
\hline $\begin{array}{l}\text { q20.1i= call for } \\
\text { interview }\end{array}$ & 7,0962 & 3,439 &, 508 &, 862 \\
\hline $\begin{array}{l}\text { q20.1p=consider } \\
\text { suitable }\end{array}$ & 7,5115 & 2,621 &, 814 &, 554 \\
$\begin{array}{l}\text { q20.1sl= short } \\
\text { listed }\end{array}$ & 7,6308 & 2,558 &, 653 &, 733 \\
\hline
\end{tabular}

Table 3. Reliability analysis of the combination impact of low quality resume and high physical attractiveness on hireability-sellectability index

Reliability Statistics

\begin{tabular}{r|r} 
Cronbach's Alpha & N of Items \\
\hline, 879 & 3 \\
\hline
\end{tabular}

Item-Total Statistics

\begin{tabular}{l|r|r|r|r}
\hline $\begin{array}{l}\text { Low quality resume with } \\
\text { high attractiveness }\end{array}$ & $\begin{array}{c}\text { Scale Mean if } \\
\text { Item Deleted }\end{array}$ & $\begin{array}{c}\text { Scale Variance if } \\
\text { Item Deleted }\end{array}$ & $\begin{array}{c}\text { Corrected Item-Total } \\
\text { Correlation }\end{array}$ & $\begin{array}{c}\text { Cronbach's Alpha if } \\
\text { Item Deleted }\end{array}$ \\
\hline $\mathrm{q} 20.2 \mathrm{i}=$ call for interview & 4,7192 & 3,523 &, 706 &, 841 \\
\hline $\mathrm{q} 20.2 \mathrm{p}=$ consider suitable & 4,9038 & 3,446 &, 759 &, 766 \\
\hline $\mathrm{q} 20.2 \mathrm{sl}=$ short listed & 4,9000 & 3,318 &, 836 \\
\hline
\end{tabular}

Table 4. Reliability analysis of physical attractiveness impact on hireability on stage of interview process

Reliability Statistics

\begin{tabular}{r|r}
\hline \multicolumn{1}{c|}{$\begin{array}{c}\text { Cronbach's } \\
\text { Alpha }\end{array}$} & N of Items \\
\hline, 931 & 3 \\
\hline
\end{tabular}

Item-Total Statistics

\begin{tabular}{l|r|r|r|r}
\hline $\begin{array}{l}\text { Physical } \\
\text { Attractiveness }\end{array}$ & $\begin{array}{c}\text { Scale Mean if } \\
\text { Item Deleted }\end{array}$ & $\begin{array}{c}\text { Scale Variance if } \\
\text { Item Deleted }\end{array}$ & $\begin{array}{l}\text { Corrected } \\
\text { Item-Total } \\
\text { Correlation }\end{array}$ & \multicolumn{1}{c}{$\begin{array}{c}\text { Cronbach's Alpha if } \\
\text { Item Deleted }\end{array}$} \\
\hline $\begin{array}{l}\text { q24.1=hire } \\
\text { q24.1= consider } \\
\text { suitable }\end{array}$ & 6,3500 & 4,097 &, 857 &, 901 \\
\hline $\begin{array}{l}\text { Q24.1= second } \\
\text { interview }\end{array}$ & 6,4885 & 4,112 &, 895 &, 871 \\
\hline
\end{tabular}


The new indicators (Hireability, Sellectability) were tested for their credibility by calculating the Cronbach's alpha factor both for the stage of resume screening (table 1) and the stage of interview process as well (table 4). Moreover we tested the credibility of indicator for the case of different combination among physical attractiveness and quality of resume (table 2, 3). The results of the credibility analysis showed that indicators are reliable in all cases with Cronbach's alpha taken values greater than 0.7 , as defined in the literature

\subsection{Questionnaire}

Questionnaire was divided in two parts. First part considers resume and characteristics on it that are considered important factors that recruiters evaluate in stage of screening applicants throw their resumes. Second part referred to interview process and attributes, qualifications of candidates that considered significant by recruiters during selection process. Questionnaire was constituted of fifty five questions of which twenty three of them referred to resume, thirty referred to interview process and two was referred to selection methods. The questions concerned the investigation of the impact and degree of importance of a number of characteristics and qualifications of candidates that employers', interviewers take into account at the stage of examination of CVS and during interview process. Indicatively, among others, they were investigated as such characteristics of the candidates' demographics, formal qualifications, studies, relative or irrelative, working experience, previous status of employment or unemployment spells, personality, employability skills, personality types, verbal communication and body language, physical attractiveness, person to the job fit, person to organization fit, extracurricular activities and other important criteria.

\subsection{Research Sample}

A total of two hundred sixty (260) questionnaires were gathered fully completed. The questionnaire was distributed to various businesses all over Greece, printed one by one, with face to face communication and contact with participants. An initial telephone communication or an email was conducted in order to inform them about the survey and to ask for the permission for their participation. This process was considered as most appropriate first because it provided the opportunity for interaction with the participants and gave the opportunity to provide additional information and clarifications on the questionnaire and the research, and secondly had the advantage of gathering a large number of questionnaire replies in a relatively short time that ensures the homogeneity, validity and relevance of the sample. The questionnaire was addressed to professional recruiters of consulting companies, directors, personnel managers and employers. The companies, enterprises which responded were form different sectors such as commerce, industry, manufactures, services, telecoms, constructions from private sector and companies for common wealth of broader public sector mainly from city of Athens and Thessaloniki. Sample has covered all sizes such as small, medium, large and very large companies. The questionnaire records and portrays personal assessments, evaluations of participants, as it is customary to apply as a practice in relevant scientific research (Saunders, \& Zuzel, 2010). The sample of two hundred and sixty people included participants as an employer, Human resources manager, professional recruitment consultants and executives who are responsible 
for recruiting workers from different work fields and different geographic areas. Attributes of participants that may affect results and are related to demographic or social characteristics such as age, gender, position etc. are also investigated in this questionnaire.

Table 5. Gender of participants

\begin{tabular}{l|c|c}
\hline \multicolumn{1}{c|}{ Gender } & \# of participants & Percentage $(\%)$ \\
\hline Male & 176 & 67,7 \\
\hline Female & 84 & 32,3 \\
\hline Total & 260 & 100,0 \\
\hline
\end{tabular}

The majority of participants in the sample are male (67.7\%), followed by the percentage of female $(32.3 \%)$, (table 3$)$.

Table 6. Size of Companies

\begin{tabular}{l|l|r|r|r|r}
\hline \multicolumn{2}{c|}{} & Frequency & Percent & Valid Percent & $\begin{array}{c}\text { Cumulative } \\
\text { Percent }\end{array}$ \\
\hline \multirow{4}{*}{\begin{tabular}{l} 
Valid \\
\multicolumn{1}{c|}{}
\end{tabular}} & 110 & 42,3 & 42,3 & 42,3 \\
\cline { 2 - 6 } & Microfirm & 48 & 18,5 & 18,5 & 60,8 \\
\cline { 2 - 6 } & Small & 23 & 8,8 & 8,8 & 69,6 \\
\cline { 2 - 6 } & Medium & 27 & 10,4 & 10,4 & 80,0 \\
\cline { 2 - 6 } & Large & 21 & 8,1 & 8,1 & 88,1 \\
\cline { 2 - 6 } & Very large & 31 & 11,9 & 11,9 & 100,0 \\
\cline { 2 - 6 } & Megafirm & 260 & 100,0 & 100,0 & \\
\cline { 2 - 6 } & Total & & & & \\
\hline
\end{tabular}

The majority of businesses are microfirms $(42,3 \%)$ and small $(18,5 \%)$ which are the main backbone of entrepreneurship in Greece

Table 7. Work status of participants

\begin{tabular}{|c|c|c|c|c|c|}
\hline \multicolumn{6}{|c|}{ Position } \\
\hline & & Frequency & Percent & Valid Percent & $\begin{array}{c}\text { Cumulative } \\
\text { Percent }\end{array}$ \\
\hline \multirow[t]{6}{*}{ Valid } & Recruiters & 55 & 21,2 & 21,2 & 21,2 \\
\hline & Personnel Managers & 34 & 13,1 & 13,1 & 34,2 \\
\hline & CEO & 24 & 9,2 & 9,2 & 43,5 \\
\hline & Department Head & 69 & 26,5 & 26,5 & 70,0 \\
\hline & Owner-Employer & 78 & 30,0 & 30,0 & 100,0 \\
\hline & Total & 260 & 100,0 & 100,0 & \\
\hline
\end{tabular}

The largest share $(30 \%)$ of the sample participants are employers, $(26,5 \%)$ is Head of Department, $(21,2 \%)$ is Professionals Recruiters, $(13,1 \%)$ are Personnel Managers' and the remaining $(9,2 \%)$ are Chief Executive Officers-CEO (Table 7) 
Table 8. Sector

\begin{tabular}{|c|c|c|c|c|c|}
\hline \multicolumn{6}{|c|}{ Sector } \\
\hline & & Frequency & Percent & Valid Percent & $\begin{array}{c}\text { Cumulative } \\
\text { Percent }\end{array}$ \\
\hline \multirow[t]{4}{*}{ Valid } & Public & 16 & 6,2 & 6,2 & 6,2 \\
\hline & Private & 211 & 81,2 & 81,2 & 87,3 \\
\hline & Consulting & 33 & 12,7 & 12,7 & 100,0 \\
\hline & Total & 260 & 100,0 & 100,0 & \\
\hline
\end{tabular}

The largest share $(81,2 \%)$ of the respondents were from private sector companies, $(12,7 \%)$ work in HR consulting companies, and the remaining $(6,2 \%)$ work in Public sector for common wealth companies

\section{Statistic Analysis and Results}

The influence of the natural attractiveness of candidates in the decisions of employer, interviewers in the process of selecting staff in the evaluation stage of their CVs

Table 9. Affect of Physical attractiveness at the evaluation stage of CVS

Descriptive Statistics

\begin{tabular}{l|r|r|r|r|r}
\hline & N & Minimum & \multicolumn{1}{c|}{ Maximum } & \multicolumn{1}{c}{ Mean } & \multicolumn{1}{|c}{ Std. Deviation } \\
\hline Q-13= Physical & 260 & 1,00 & 5,00 & 2,7987 &, 96800 \\
Attractiveness impact & 260 & & & & \\
\hline Valid N (listwise) & 260 & & \\
\hline
\end{tabular}

In table (9) we observe the average mean of the responses of participants $(n=260)$ as to the effect of the candidates' physical attractiveness on employers' decisions to consider them as, selectable, eligible at the evaluation stage of their CVS. Based on the descriptive statistical analysis, we observe that the criterion of physical attractiveness Q13 takes average value, Mean $=2,7987$, which means that the factor Physical Attractiveness of the candidates affects employers' decisions at least, moderately to sufficiently in the first stage of the selection which is to evaluate candidates ' CVs.

The comparative effect between combinations of a candidate with high quality $C V$ and small attractiveness, compared to a candidate with low quality $C V$ and particular attractiveness, in the decisions of employers, interviewers at the stage of evaluation their CVs.

Table 10. High quality CV and small attractiveness compared with low quality CV and high attractiveness

\begin{tabular}{l|r|r|r|r|r}
\hline & N & \multicolumn{1}{c}{ Minimum } & \multicolumn{1}{c}{ Maximum } & \multicolumn{1}{c}{ Mean } & Std. Deviation \\
\hline $\begin{array}{l}\text { Q20-1= High Quality } \\
\text { Resume+ Low Attractiveness }\end{array}$ & 260 & 1,33 & 5,00 & 3,7064 &, 80839 \\
\hline Q20-2= Low Quality & 260 & 1,00 & 5,00 & 2,4205 &, 89907 \\
Resume+ High Attractiveness & 260 & & & & \\
\hline Valid N (listwise) & 2605 & & \\
\hline
\end{tabular}


In table (10) we observe the average of the responses of the sampled participants $(n=260)$ as to the effect of the impression that creates two different combinations of candidates, in the decisions of employers to consider a candidate as suitable (eligible) for employment-recruitment during the evaluation stage of these CVS. The combination of a candidate with high quality CV (significant experience, studies, distinctions) with low physical attractiveness, compared with a candidate with low quality CV (not appreciable experience, studies, etc.) but high physical attractiveness. Based on the descriptive statistical analysis we observe that the first combination of high quality CV (typical qualifications, work experience and) with little physical attractiveness Q20-1, takes the maximum value Mean $=3.7064$ i.e. quite above the waist weighting of the Likert scale, while the second combination candidate with low quality CV and high physical attractiveness receives Q20-2, Mean $=2,4205$ well below average on the scale of responses, which means that the criterion of high quality $\mathrm{CV}$ is much more important than the natural attractiveness of candidates and candidates with high quality $\mathrm{CV}$ but low physical attractiveness are significantly more likely to be perceived by the employers, interviewers as suitable for employment-recruitment during the evaluation stage of their CVS according to the hireability, sellectability index, which we have defined

Control of a statistically significant difference

$\mathrm{T}=$ Test

Paired Samples Statistics

\begin{tabular}{l|l|r|r|r|r}
\hline \multicolumn{2}{c|}{} & \multicolumn{1}{c|}{ Mean } & N & \multicolumn{1}{c}{ Std. Deviation } & \multicolumn{1}{c}{ Std. Error Mean } \\
\hline \multirow{2}{*}{ Pair 1 } & Q20-1 & 3,7064 & 260 &, 80839 &, 05013 \\
\cline { 2 - 6 } & Q20-2 & 2,4205 & 260 &, 89907 &, 05576 \\
\hline
\end{tabular}

Paired Samples Correlations

\begin{tabular}{l|l|r|r|r}
\hline \multicolumn{2}{l}{} & \multicolumn{1}{c|}{ N } & \multicolumn{1}{c}{ Correlation } & \multicolumn{1}{c}{ Sig. } \\
\hline Pair 1 & Q20-1 \& Q20-2 & 260 &,- 060 &, 338 \\
\hline
\end{tabular}

Table 11. Test of significant difference

Paired Samples Test

\begin{tabular}{|c|c|c|c|c|c|c|c|c|c|}
\hline & & \multicolumn{5}{|c|}{ Paired Differences } & \multirow[b]{3}{*}{$\mathrm{T}$} & \multirow[b]{3}{*}{$\mathrm{df}$} & \multirow{3}{*}{$\begin{array}{c}\text { Sig. } \\
\text { (2-tailed) }\end{array}$} \\
\hline & & \multirow[b]{2}{*}{ Mean } & \multirow{2}{*}{$\begin{array}{c}\text { Std. } \\
\text { Deviation } \\
\end{array}$} & \multirow{2}{*}{$\begin{array}{c}\text { Std. Error } \\
\text { Mean }\end{array}$} & \multicolumn{2}{|c|}{$\begin{array}{c}95 \% \text { Confidence } \\
\text { Interval of the } \\
\text { Difference }\end{array}$} & & & \\
\hline & & & & & Lower & Upper & & & \\
\hline $\begin{array}{c}\text { Pair } \\
1\end{array}$ & $\begin{array}{l}\text { Q20-1 - } \\
\text { Q20-2 }\end{array}$ & $\begin{array}{c}1,2859 \\
0\end{array}$ & 1,24442 & ,07718 & 1,13393 & 1,43787 & 16,662 & 259 &, 000 \\
\hline
\end{tabular}

To check if there is a statistically significant difference between high quality $\mathrm{CV}$ and low attractiveness combinations, compared to the candidate's low quality of $\mathrm{CV}$ and high attractiveness combination, regarding the degree of impact In employers ' decisions, we 
carried out a materiality check with the paired sample T-test (table 11)

Control generates level of significance $p=0,000<0.05$

$\mathrm{t}(259)=16,662$

$\mathrm{p}=0,000$

Thus there is a statistically significant difference between these two combinations of candidates, in the decisions of the interviewers in the process of evaluating their CVs

The importance, impact of the natural attractiveness, presence (appearance) of candidates in the decisions of employers, interviewers in the process of selecting staff during the interview process.

Table 12. The significance, effect of candidates' physical attractiveness during interview process

\begin{tabular}{l|r|r|r|r|r}
\multicolumn{7}{|c}{ DescriptiveStatistics } \\
\hline & \multicolumn{1}{|c|}{ N } & \multicolumn{1}{c|}{ Minimum } & \multicolumn{1}{c}{ Maximum } & \multicolumn{1}{l}{ Mean } & \multicolumn{1}{c}{ Std. Deviation } \\
\hline Q-29= Physical & 260 & 1,00 & 5,00 & 3,2218 & 1,00404 \\
Attractiveness & 260 & & & & \\
\hline Valid N (listwise) & & & & \\
\hline
\end{tabular}

In Table (12) we observe the average of the responses of the sampled participants $(n=260)$ as to the significance of the employers, interviewers to the attractive appearance, presence of the candidates, during the interview, regarding employers' decisions to consider a candidate as suitable for employment-recruitment in this process. Based on the descriptive statistical analysis we observe that physical attractiveness, Q29 receives an average value of mean = 3.2218 i.e. quite above the average weighting of the Likert scale, which means that the natural attractiveness of the candidates as a criterion perceived by employers as important enough in their decisions to consider candidates as suitable for employment-recruitment for a job according to the hireability, sellectability index, we have defined.

It is worth seeing in comparison and checking the degree of impact of attractiveness of the candidates as a selection criterion at the two different stages of the selection procedure, i.e. at the evaluation stage of the CV where the criterion, attractiveness of candidates (based on attachment of a photograph to their $\mathrm{CV}$ ) where $\mathrm{Q} 13$ receives an average value mean $=2.7987$ and at the stage of the interview process where the same criterion receives an average value where Q29, mean = 3,2218 clearly greater as materiality than the first stage.

Control of a statistically significant difference

T-Test

\begin{tabular}{l|l|r|r|r|r}
\multicolumn{7}{c}{ Paired Samples Statistics } \\
\hline \multirow{2}{*}{ Pair 1 } & \multicolumn{1}{c}{ Mean } & N & \multicolumn{1}{c}{ Std. Deviation } & \multicolumn{1}{c}{ Std. Error Mean } \\
\cline { 2 - 6 } & Q-13 & 2,7987 & 260 &, 96800 &, 06003 \\
\cline { 2 - 6 } & Q-29 & 3,2218 & 260 & 1,00404 &, 06227 \\
\hline
\end{tabular}




\begin{tabular}{l|r|r|r|r}
\multicolumn{7}{c}{ Paired Samples Correlations } \\
\hline \multicolumn{2}{|c|}{} & N & Correlation & \multicolumn{1}{c}{ Sig. } \\
\hline Pair 1 & Q-13 \& Q-29 & 260 &, 523 &, 000 \\
\hline
\end{tabular}

Table 13. Control of significant difference of physical attractiveness impact between resume screening stage and interview process stage

Paired Samples Test

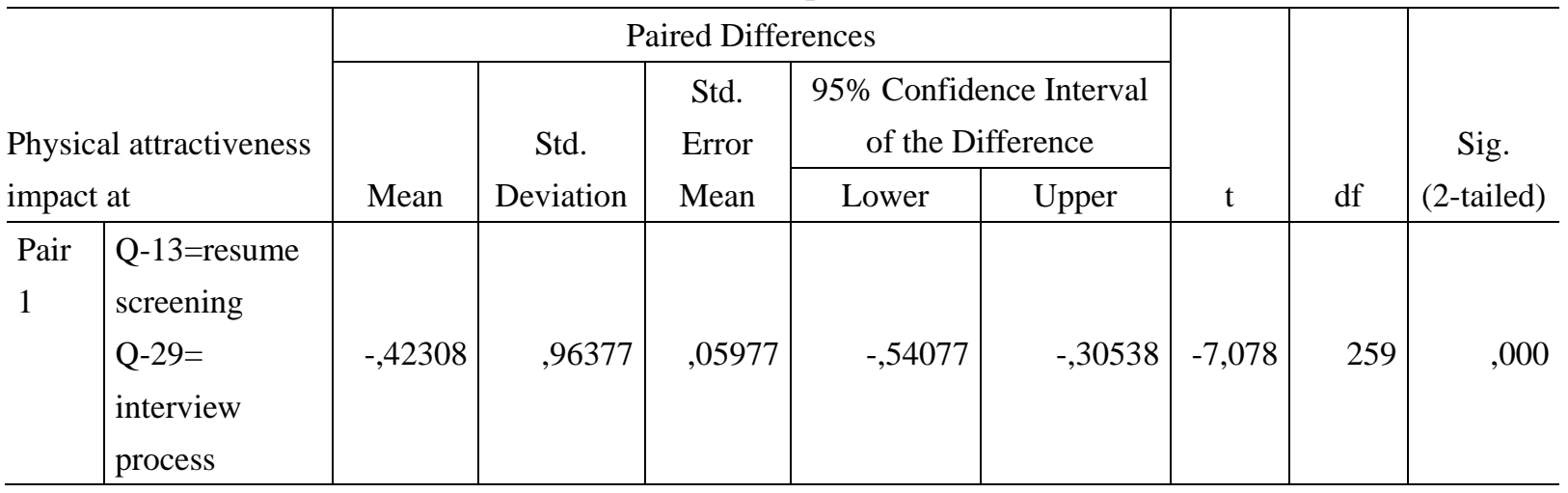

To check whether there is a statistically significant difference in the relative impact of the attractiveness of candidates between the stage of evaluation of the candidates ' CVs and the stage of the interview to the extent of its effect on the decisions of employers, we performed a materiality check with the paired sample T-test. (table 13)

Control generates level of significance $p=0,000<0.05$

$t(259)=-7,078$

$\mathrm{p}=0,000$

Therefore there is a statistically significant difference in the impact of candidates' attractiveness in the decisions of the interviewers, between the stage of the evaluation of their $\mathrm{CVs}$ and in interview stage. This means that the criterion of attractiveness of candidates is statistically more important and affects more employers, interviewers at the stage of the interview process and less at the stage of evaluation candidates resumes in their decisions to consider a candidate as suitable for employment, recruitment in accordance with the hireability, sellectability index which we previously defined. Possibly this observed increase in the materiality of this criterion at the interview stage compared to the stage of the evaluation of the $\mathrm{CV}$ is due to the fact that at this stage, i.e. the interview, the employers, interviewers correlate this criterion according to the profile and requirements of the job they want to cover and therefore this criterion the attractiveness clearly becomes more perceptible and more important during the interview process and less means from the curriculum vitae

\section{Discussion}

We examined the impact of candidates' physical attractiveness on selection recruiters' decisions during their resume screening and interview process. Hypothesis (1) and (2) have been confirmed. Our results show that physical attractiveness has a positive impact on recruiters and employers decisions both in stage of resume screening as well as in the stage of 
interview process which are in line with the results of other previous research (Dipboye,et al 1975; Bartram, et al 1995; Davison et al.,2011; Hosoda, Stone-Romero, and Coats, 2003; Shahani-Denning et al., 2011; Abel, and Deitz, 2008; Johnson, et al.,2010; Gilmore, et al 1986; Tedeschi \& Melburg,1984; Schmitt, 1976; Cash, et al. 1977; Kinicki \& Lockwood,1985; Subhani, 2012).

Hypothesis (3) hasn't been confirmed. Influence of physical attractiveness is higher during interview process stage and less in stage of resume screening decisions. There is a statistically significant difference in the impact of physical attractiveness of candidates between these two stages. According to the knowledge so far we have, other research has not studied the relative influence of the natural attractiveness of candidates in the decisions of interviewers between the stage of evaluation of their CVs and the stage of Interview, thus we can't correlate, collate, the results of our study with other similar research in order to have a more holistic comparative view. Hypothesis (4) which is relative impact between qualities of resume and physical attractiveness on recruiters' decisions has been also checked and been confirmed. Results show that quality (experience, qualifications) resume has higher impact than physical attractiveness on selection outcomes when we compare a candidate who has high quality resume and be less attractive, in comparison with a co candidate who has lower quality resume but is more attractive. Thus discrimination, bias among attractive and less attractive candidates doesn't occur. There is a statistically significant difference among candidates with quality resume and less attractiveness and candidates with inferior resumes and higher attractiveness. These results are in consistence with the results of previous researches (Dipboye,et al 1977; Watcins and Johnston 2000)

\section{Conclusions and Suggestions}

It is obvious that physical attractiveness has an influence and significant impacts on personnel selection outcomes during resume screening process, as well as in interview process. Despite the fact that, there are definitely situations in which candidates physical attractiveness can be considered as a job-relative positive or required attribute which can contribute to job outcomes, other also critical qualifications of candidates on hiring decisions could be fair, necessary and essential. In order to eliminate the impact of physical attractiveness bias in employment selection outcomes a set of specific actions and methods can be undertaken. An initiative approach is having recruiters alerted about the physical attractiveness impacts on their hiring decisions and be well informed regarding issues of bias or discrimination that might occur. Moreover, other steps can be taken such as training recruiters, personnel managers and employers to have in mind and take care about the influence that subjective factors such a physical attractiveness or 'similar to me', 'hello effect' cases phenomena, might occur during selection practices, in order to eliminate that influence to their hiring decisions. Additional practice is to utilize formulated, structured interview process which has more reliable outcomes by reducing influence of physical attractiveness or relative bias phenomena (Barrick et al., 2009; Jabbour, 2009). Interviews shall be well structured to equal asses certain values and attributes of candidates and focus on specific objectively, impartially qualifications such as prior work experience, social skills, knowledge of the particular work, conscientiousness, cognitive ability (Robertson and Smith, 
2001, p. 456) and person to organization fit (Rynes \& Gerhart,1990) which can be measured throw interview process. Recruiters, employers should also utilize and combine various personnel selection methods such as work-sample tests, cognitive ability tests, references, biographical information, personality inventories, as none of these require knowledge of physical attractiveness and cannot be influenced by it (Noe et al., 2006) and concurrently to conduct cross check interviews with other recruiters switching its other, or conducting panel interviews' in order to avoid or eliminate impact of subjective criteria. Despite the fact that attractiveness has an impact to recruiters and employers decisions, it is well supported that its influence can be reduced and eliminated in significant extent. A combined implementation of the above techniques and actions can contribute effectively to this result, enhancing by this way to the reliability and validity of employee selection process.

\subsection{Research Contribution}

This study investigated the impact of the natural attractiveness of candidates on employers', interviewers' decisions and its results reinforce and contribute to the existing knowledge on this subject with research emphasis in Greece case. The focus and contribution of this research is to explore the different degree of influence of natural attractiveness between the evaluation stage of the candidates' CVs and the stage of the interview. Among them, it was found that the physical attractiveness affects both stages of the staff selection process and there is a statistically significant difference in the impact of attractiveness which is higher in the interview stage. In addition, the results of this research showed that despite the fact that the effect of physical attractiveness is occurs in the two stages of selection process, however its effect is lower compared to a candidate that lags in attractiveness but outweighs in quality of resume qualification, result that agrees and enhances the results of other corresponding surveys contributing to relevant knowledge.

\section{References}

Abel, M. H., \& Deitz, M. (2008). Smiling, Job Qualifications, and Ratings of Job Applicants. American Journal of Psychological Research, 4(1).

Arvey, R. D., \& Campion, J. E. (1982). THE EMPLOYMENT INTERVIEW: A SUMMARY AND REVIEW OF RECENT RESEARCH 1. Personnel psychology, 35(2), 281-322. https://doi.org/10.1111/j.1744-6570.1982.tb02197.x

Barrick, M., Shaffer, J., \& DeGrassi, S. (2009). What you see may not be what you get: relationships among self-presentation tactics, and ratings of interview performance, Journal of Applied Psychology, 94(6), 1394-1411. https://doi.org/10.1037/a0016532

Bartram, D. (2000). Internet Recruitment and Selection: Kissing Frogs to Find Princes. International Journal of Selection and Assessment, 8(4). https://doi.org/10.1111/1468-2389.00155

Bartram, D., Lindley, P. A., Marshall, L., \& Foster, J. (1995). The recruitment and selection of young people by small businesses. Journal of Occupational and Organizational Psychology, 68(4), 339-358. https://doi.org/10.1111/j.2044-8325.1995.tb00592.x 
Beehr, T. A., \& Gilmore, D. C. (1982). Applicant attractiveness as a perceived job-relevant variable in selection of management trainees. Academy of Management Journal, 25(3), 607-617. https://doi.org/10.2307/256084

Bright, J. E., \& Hutton, S. (2000). The impact of competency statements on resumes for short-listing decisions. International Journal of Selection and Assessment, 8(2), 41-53. https://doi.org/10.1111/1468-2389.00132

Brown, B. K., \& Campion, M. A. (1994). Biodata phenomenology: Recruiters' perceptions and use of biographical information in resume screening. Journal of Applied Psychology, 79(6), 897. https://doi.org/10.1037/0021-9010.79.6.897

Burger, J. M., \& Caldwell, D. F. (2000). Personality, social activities, job-search behavior and interview success: Distinguishing between PANAS trait positive affect and NEO extraversion. Motivation and Emotion, 24(1), 51-62. https://doi.org/10.1023/A:1005539609679

Cable, D. M., \& Gilovich, T. (1998). Looked over or overlooked? Prescreening decisions and postinterview evaluations. Journal of applied psychology, 83(3), 501. https://doi.org/10.1037/0021-9010.83.3.501

Cable, D. M., \& Judge, T. A. (1997). Interviewers' perceptions of person-organization fit and organizational selection decisions. Journal of Applied psychology, 82(4), 546. https://doi.org/10.1037/0021-9010.82.4.546

Caldwell, D. F., \& Burger, J. M. (1998). Personality characteristics of job applicants and success in screening interviews. Personnel Psychology, 51(1), 119-136. https://doi.org/10.1111/j.1744-6570.1998.tb00718.x

Cash, T. F., Gillen, B., \& Burns, D. S. (1977). Sexism and beautyism in personnel consultant decision making. Journal of applied psychology, 62(3), 301. https://doi.org/10.1037/0021-9010.62.3.301

Cuddy, A. J., Wilmuth, C. A., Yap, A. J., \& Carney, D. R. (2015). Preparatory power posing affects nonverbal presence and job interview performance. Journal of Applied Psychology, 100(4), 1286. https://doi.org/10.1037/a0038543

Davison, H. K., Maraist, C., \& Bing, M. N. (2011). Friend or foe? The promise and pitfalls of using social networking sites for HR decisions. Journal of Business and Psychology, 26(2), 153-159. https://doi.org/10.1007/s10869-011-9215-8

Desrumaux, P., De Bosscher, S., \& Leoni, V. (2009). Effects of facial attractiveness, gender, and competence of applicants on job recruitment. Swiss Journal of Psychology, 68(1), 33-42. https://doi.org/10.1024/1421-0185.68.1.33

Dion, K., Berscheid, E., \& Walster, E. (1972). What is beautiful is good. Journal of personality and social psychology, 24(3), 285. https://doi.org/10.1037/h0033731

Dipboye, R. L. (1992). Selection interviews: Process perspectives. South-Western Pub.

Dipboye, R. L., Arvey, R. D., \& Terpstra, D. E. (1977). Sex and physical attractiveness of raters and applicants as determinants of resume evaluations. Journal of Applied Psychology, 62(3), 288. https://doi.org/10.1037/0021-9010.62.3.288 
Dipboye, R. L., Fontenelle, G. A., \& Garner, K. (1984). Effects of previewing the application on interview process and outcomes. Journal of Applied Psychology, 69(1), 118. https://doi.org/10.1037/0021-9010.69.1.118

Djabatey, E. N. (2012). Recruitment and Selection Practices of Organisations: A Case Study of HFC Bank (Gh) Ltd (Doctoral dissertation).

Gamage, A. S. (2014). Recruitment and selection practices in manufacturing SMEs in Japan: An analysis of the link with business performance. Ruhuna Journal of Management and Finance, 1(1), 37-52. https://doi.org/10.4038/suslj.v13i1.7668

Gilmore, D. C., \& Ferris, G. R. (1989). The effects of applicant impression management tactics on interviewer judgments. Journal of Management, 15(4), 557-564. https://doi.org/10.1177/014920638901500405

Gilmore, D. C., Beehr, T. A., \& Love, K. G. (1986). Effects of applicant sex, applicant physical attractiveness, type of rater and type of job on interview decisions. Journal of $\begin{array}{llr}\text { occupational } & \text { psychology, } & \text { 103-109. }\end{array}$ https://doi.org/10.1111/j.2044-8325.1986.tb00217.x

Heilman, M. E., \& Saruwatari, L. R. (1979). When beauty is beastly: The effects of appearance and sex on evaluations of job applicants for managerial and nonmanagerial jobs. Organizational Behavior and Human Performance, 23(3), 360-372. https://doi.org/10.1016/0030-5073(79)90003-5

Higgins, C. A., \& Judge, T. A. (2004). The effect of applicant influence tactics on recruiter perceptions of fit and hiring recommendations: a field study. Journal of Applied Psychology, 89(4), 622. https://doi.org/10.1037/0021-9010.89.4.622

Hosoda, M., Stone-Romero, E. F., \& Coats, G. (2003). The effects of physical attractiveness on job-related outcomes: A meta-analysis of experimental studies. Personnel psychology, 56(2), 431-462. https://doi.org/10.1111/j.1744-6570.2003.tb00157.x

Jabbour, K. (2009). The effect of the interview structure on the physical attractiveness bias (Doctoral dissertation, Concordia University

Johnson, S. K., Podratz, K. E., Dipboye, R. L., \& Gibbons, E. (2010). Physical attractiveness biases in ratings of employment suitability: Tracking down the "beauty is beastly" effect. The Journal of social psychology, 150(3), 301-318. https://doi.org/10.1080/00224540903365414

King, M. R., \& Manaster, G. J. (1977). Body image, self-esteem, expectations, self-assessments, and actual success in a simulated job interview. Journal of Applied Psychology, 62(5), 589. https://doi.org/10.1037/0021-9010.62.5.589

Kinicki, A. J., \& Lockwood, C. A. (1985). The interview process: An examination of factors recruiters use in evaluating job applicants. Journal of Vocational Behavior, 26(2), 117-125. https://doi.org/10.1016/0001-8791(85)90012-0

Knouse, S. B. (1994). Impressions of the resume: The effects of applicant education, experience, and impression management. Journal of Business and Psychology, 9(1), 33-45. https://doi.org/10.1007/BF02230985 
Marlowe, C. M., Schneider, S. L., \& Nelson, C. E. (1996). Gender and attractiveness biases in hiring decisions: Are more experienced managers less biased?. Journal of applied psychology, 81(1), 11. https://doi.org/10.1037/0021-9010.81.1.11

Noe, R. A., Hollenbeck, J. R., Gerhart, B., \& Wright, P. M. (2017). Human resource management: Gaining a competitive advantage. New York, NY: McGraw-Hill Education.

Robertson, I. T., \& Smith, M. (2001). Personnel selection. Journal of occupational and Organizational psychology, 74(4), 441-472. https://doi.org/10.1348/096317901167479

Roebken, H. (2010). Similarity attracts: An analysis of recruitment decisions in academia. Educational Management Administration \& Leadership, 38(4), 472-486. https://doi.org/10.1177/1741143210368264

Rynes, S. L., Barber, A. E., \& Varma, G. H. (2000). Research on the employment interview: Usefulness for practice and recommendations for future research. In C. L. Cooper \& E. A. Locke (2013). Industrial and organizational psychology: Linking theory with practice (pp. 250-277). Malden, MA: Blackwell.

Rynes, S., \& Gerhart, B. (1990). Interviewer assessments of applicant "fit": An exploratory investigation. Personnel psychology, 43(1), 13-35. https://doi.org/10.1111/j.1744-6570.1990.tb02004.x

Saunders, V., \& Zuzel, K. (2010). Evaluating employability skills: Employer and student perceptions. Bioscience education, 15(1), 1-15. https://doi.org/10.3108/beej.15.2

Schmitt, N. (1976). SOCIAL AND SITUATIONAL DETERMINANTS OF INTERVIEW DECISIONS: IMPLICATIONS FOR THE EMPLOYMENT INTERVIEW 1. Personnel psychology, 29(1), 79-101. https://doi.org/10.1111/j.1744-6570.1976.tb00404.x

Shahani-Denning, C., Andreoli, N., Snyder, J., Tevet, R., \& Fox, S. (2011). The effects of physical attractiveness and gender on selection decisions: An experimental study. International Journal of Management, 28(4), 16.

Shahani-Denning, C., Dudhat, P., Tevet, R., \& Andreoli, N. (2010). Effect of physical attractiveness on selection decisions in India and the united states. International Journal of Management, 27(1), 37.

Sivabalan, Loganesh; Yazdanifard, Dr. Rashad; Ismail, Nor Haslinda. (2014). How to Transform the Traditional Way of Recruitment into Online System. International Business Research, Canadian Center of Science and Education. 7. 178-185. https://doi.org/10.5539/ibr.v7n3p178

Stevens, C. K., \& Kristof, A. L. (1995). Making the right impression; A field study of applicant impression management during job interviews. Journal of Applied Psychology, 80, 587-606. https://doi.org/10.1037/0021-9010.80.5.587

Subhani, M. I. (2012). Impact of physical attractiveness on selection and recruitment process. Tedeschi, J. T., \& Melburg, V. (1984). Impression management and influence in the organization. Research in the sociology of organizations, 3(31-58). 


\section{MINinstitutemk}

International Journal of Human Resource Studies

ISSN 2162-3058

2019, Vol. 9, No. 3

Thoms, P., McMasters, R., Roberts, M. R., \& Dombkowski, D. A. (1999). Resume characteristics as predictors of an invitation to interview. Journal of Business and Psychology, 13(3), 339-356. https://doi.org/10.1023/A:1022974232557

Tsai, W. C., Chen, C. C., \& Chiu, S. F. (2005). Exploring boundaries of the effects of applicant impression management tactics in job interviews. Journal of Management, 31(1), 108-125. https://doi.org/10.1177/0149206304271384

Wade, K. J., \& Kinicki, A. J. (1997). Subjective applicant qualifications and interpersonal attraction as mediators within a process model of interview selection decisions. Journal of Vocational Behavior, 50(1), 23-40. https://doi.org/10.1006/jvbe.1996.1538

Wade, T. J. (2000). Evolutionary theory and self-perception: sex differences in body esteem predictors of self-perceived physical and sexual attractiveness and self esteem. International Journal of Psychology, 35(1), 36-45. https://doi.org/10.1080/002075900399501

Wade, T. J. (2003). Evolutionary theory and African American self-perception: Sex differences in body esteem predictors of physical and sexual attractiveness, and self-esteem. Journal of Black Psychology, 29(2) 123-141. https://doi.org/10.1177/0095798403029002001

Watkins, L. M., \& Johnston, L. (2000). Screening job applicants: The impact of physical attractiveness and application quality. International Journal of selection and assessment, 8(2), 76-84. https://doi.org/10.1111/1468-2389.00135

Werbel, J. D., \& Looney, S. (1994). The use of selection criteria for campus interviews. International Journal of Selection and Assessment, 2(1), 28-36. https://doi.org/10.1111/j.1468-2389.1994.tb00126.x

Zedeck, S. E. (2011). APA handbook of industrial and organizational psychology, Vol 2: Selecting and developing members for the organization. https://doi.org/10.1037/12170-000

\section{Short CV}

Andreas Dimopoulos has been researching the issue of job placement, personnel selection, employability and labor market, is an author of a book, has published articles and gave lectures with corresponding topics. He is a certified instructor, consultant and mentor of companies and provides specialized consultancy services and seminars in the fields of employment, management, employee selection, personnel evaluation and human development. He has profound experience as a manager in large multinational enterprises, as well as in Greek Public sector in Ministry of Education and National Center of Public Administration as special scientific personnel. He participated as a scientific collaborator in numerous European programs on issues of innovation, business plans, business mentoring, coaching and entrepreneurship.

\section{Copyright Disclaimer}

Copyright for this article is retained by the author(s), with first publication rights granted to the journal.

This is an open-access article distributed under the terms and conditions of the Creative Commons Attribution license (http://creativecommons.org/licenses/by/4.0/). 